\title{
Sistem Informasi Aset Intelektual Berbasis Knowledge Management System
}

\author{
Qitvirul Azij Ishari, Achmad Teguh Wibowo, Mohammad Khusnu Milad
}

\begin{abstract}
Knowledge Management System (KMS) includes the creation and management of knowledge for the development of effective and productive student intellectual assets. This research is based on observation and study of literature within the Faculty of Science and Technology of Sunan Ampel Surabaya State Islamic University. Student intellectual assets including products, works, innovations, and achievements of each study program are still lacking in terms of management. This study applies the KMS concept in managing student intellectual assets by implementing the Socialization, Externalization, Combination, Interlization (SECI) model and application development methods using ADDIE. The results of this study are in the form of KMS applications with discussion group forum features, student achievement records, student product records, and education. With this KMS application, the Faculty of Science and Technology can manage student intellectual assets as well as a medium for sharing and transferring knowledge. So that the evaluation of teaching and learning activities can be more controlled.
\end{abstract}

Index Terms-ADDIE, Intellectual Assets, Knowledge Management System, SECI Model.

Abstrak--Knowledge Management System (KMS) meliputi pembuatan dan pengelolahan pengetahuan untuk pengembangan aset intelektual mahasiswa yang efektif dan produktif. Riset ini berdasarkan observasi dan studi literatur di lingkungan Fakultas Sains dan Teknologi UIN Sunan Ampel Surabaya. Aset intelektual mahasiswa meliputi produk, karya, inovasi, dan prestasi dari setiap prodi masih terdapat kekurangan dari segi pengelolaan. Penelitian ini menerapkan konsep KMS dalam mengelola aset intelektual mahasiswa dengan mengimplementasikan model Socialization, Externalization, Combination, Interlization (SECI) serta metode pengembangan aplikasi menggunakan ADDIE. Hasil dari penelitian ini berupa aplikasi KMS dengan fitur forum grup diskusi, arsip prestasi mahasiswa, arsip

Manuscript received December 22, 2019. This work was supported in part by Sistem Informasi, Fakultas Sains dan Teknologi, Universitas Islam Negeri Sunan Ampel Surabaya.

Qitvirul Azij Ishari, Sistem Informasi, Fakultas Sains dan Teknologi, Universitas Islam Negeri Sunan Ampel Surabaya email : virulishari@gmail.com

Achmad Teguh Wibowo, Sistem Informasi, Fakultas Sains dan Teknologi, Universitas Islam Negeri Sunan Ampel Surabaya email : atw@uinsby.ac.id

Mohammad Khusnu Milad, Sistem Informasi, Fakultas Sains dan Teknologi, Universitas Islam Negeri Sunan Ampel Surabaya email :m.milad@uinsby.ac.id produk mahasiswa, dan edukasi. Dengan adanya Aplikasi KMS ini, Fakultas Sains dan Teknologi dapat mengelola aset intelektual mahasiswa serta sebagai media untuk sharing dan transfer knowledge. Sehingga evaluasi kegiatan belajar mengajar dapat lebih terkontrol.

Kata Kunci- Aset Intelektual, ADDIE, Knowledge Management System, Model SECI.

\section{Pendahuluan}

$\mathrm{P}$ RODUK dan inovasi di bidang keilmuan Sains dan Teknologi berkembang sangat pesat di era globalisasi. Untuk dapat bersaing dalam bidang keilmuan di era globalisasi, Fakultas Sains dan Teknologi UIN Sunan Ampel Surabaya mulai meningkatkan strategi kurikulum akademik yang diharapkan mahasiswa mampu menghasilkan suatu produk dari setiap pengembangan ilmu yang di dapatkan. Tidak hanya kurikulum dan fasilitas yang di tingkatkan, pengorganisasian hasil dari pengaplikasian bidang keilmuan mahasiswa juga harus di kelola dengan baik hingga menjadi suatu aset intelektual mahasiswa yang permanen dan dapat bersaing di era globalisasi.

Mahasiswa memiliki aset intelektual masih terdapat permasalahan dari segi pengelolahan, Mulai dari pencatatan aset intrlrktual masih manual sehingga penelusuran aset menjadi sulit, aset yang belum terdokumentasi oleh sistem, selain itu dari segi penggunaan kertas dan tinta menambah biaya yang lebih tinggi.

Penerapan konsep Knowledge Management System bagian dari strategi dalam mengelola sirkulasi data aset pada bidang keilmuan tertentu, data yang di dapat akan lebih mudah dicerna dan ditelusuri, selanjutnya digunakan untuk pengembangan disiplin ilmu sehingga bidang keilmuan dapat berkembang secara maksimal [1].

Aplikasi yang di bangun berbasis website bermaksud Akan lebih mudah mengakses informasi yang di berikan pada setiap user yang menggunakan aplikasi tersebut, karena dapat di akses secara online dengan menggunakan framework codeigniter dalam pengembangan aplikasi. CodeIgniter merupakan bagian dari aplikasi open source yang berupa framework PHP dengan model MVC (Model, View, Controller) berfungsi untuk membangun aplikasi web 
dinamis dengan efektif dan efesien [2].

\section{LANDASAN TEORI}

\section{A. Knowledge Management System}

KMS adalah suatu mekanisme dalam menyimpan, memelihara, dan mengorganisasikan informasi bisnis serta pekerjaan yang berhubungan dengan penciptaan berbagai informasi yang menjadi aset intelektual organisasi yang permanen [1].

Dalam menciptakan pengetahuan sendiri dibutuhkan penerapkan tacit knowledge serta mengakumulasikan mulai dari level individu. Knowledge sprial memberi kemudahan dalam penciptaan pengetahuan di mana hal itu merupakan bagian dari interaksi antara tacit knowledge dengan explicit knowledge [3]. Seperti gambar berikut :

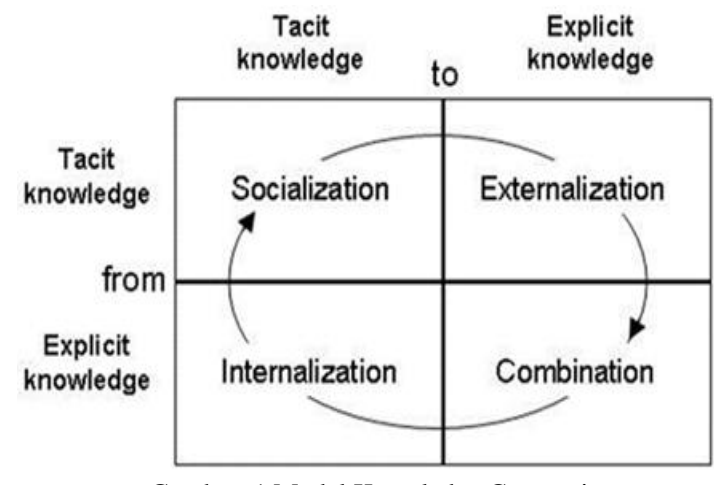

Gambar. 1 Model Knowledge Conversi

Ikujiro Nonaka dan Hirotaka Takeuchi pada tahun 1991 dan 1995, membedakan antara tacit knowledge dan explicit knowledge, dan membagi model konversi knowledge menjadi 4 cara sebagai berikut:

- Tacit knowledge ke Explicit knowledge; disebut proses Externalization.

- Tacit knowledge ke Tacit knowledge; disebut proses Socialization.

- Explicit knowledge ke Explicit knowledge; disebut proses Combination.

- Explicit knowledge ke Tacit knowledge; disebut proses Interlization.

\section{B. Knowledge Assets}

merupakan pengetahuan atau keahlian manusia yang termodifikasi, tersimpan dalam format digital maupun elektronik [4]. Manajemen strategis dari Knowledge Assets harus berfokus pada penciptaan dan penyebaran Knowledge [3]. Aset sendiri dapat dikategorikan menjadi 4 tipe:

- Experiental knowledge assets, berisi dari tacit knowledge yang dibangun dari pengalamanpengalaman karyawan. Dari assets knowledge ini, perusahaan dapat menggunakannya untuk mengetahui value waktu dan uang di benak karyawan dari kegiatan yang biasa dilakukan oleh para karyawan tersebut.

- Conceptual knowledge assets, berisi explicit knowledge yang dapat dituangkan menjadi gambar, symbol, ataupun tulisan. Dari assets ini biasanya perusahaan dapat mengetahui value waktu dan uang yang sudah tertuang ke dalam konsep/sudah menjadi standar.

- Systemic knowledge assets, berisi dari explicit knowledge yang dikemas dengan sistematis. Ini biasa disebut asset informasi, contohnya seperti teknologi, manual, dokumen-dokumen, informasi mengenai pelanggan dan pemasok, spesifikasi produk. Aset ini memiliki resiko yang sangat tinggi, karena merupakan hal penting bagi perusahaan dalam menjalankan bisnis prosesnya.

- Routine knowledge assets, berisi tacit knowledge yang sudah tertanam dan menjadi regulasi dalam operasional dan mengandung culture, praktek, dan prosedur dalam perusahaan tersebut. Contohnya proses bisnis, sistem informasi, dan database.

\section{Framework Codeigniter}

CodeIgniter adalah framework PHP yang dibuat berdasarkan kaidah model View-controller. Dengan MVC, maka memungkinkan pemisahan antara layer application-logic dan presentation. Sehingga, dalam sebuah pengembangan web, seorang programmer bisa berkonsentrasi pada core-system, sedangkan web designer bisa berkonsentrasi pada tampilan web. Menariknya, skrip PHP, query MySQL, Javascript dan CSS bisa saling terpisah, tidak dibuat dalam satu skrip berukuran besar yang membutuhkan resource besar pula untuk mengesekusinya [5]. Adapun alur program aplikasi berbasis framework Codeigniter berikut :

Gambar diatas menerangkan bahwa ketika datang sebuah user request, maka akan ditangani oleh controller, kemudian controller akan memanggil model jika memang diperlukan operasi database. Hasil dari query oleh model kemudian akan dikembalikan ke controller. Selanjutnya controller akan memanggil view yang tepat dan mengkombinasikannya dengan hasil query model. Hasil akhir dari operasi ini akan ditampilkan dibrowser,

Dalam konteks CodeIgniter dan aplikasi berbasis web, maka penerapan konsep MVC mengakibatkan kode program dapat dibagi menjadi tiga kategori, yaitu :

1. Model Kode program (berupa OOP class) yang digunakan untuk memanipulasi database.

2. View Berupa template $\mathrm{html} / \mathrm{xml}$ atau php untuk menampilkan data pada browser

3. Controller Kode program (berupa OOP class) yang digunakan untuk mengontrol aliran aplikasi (sebagai pengontol model dan View).

\section{Website}

Sebuah Website, atau dikenal juga dengan situs web, adalah sekumpulan halaman yang menampilkan data data berupa teks, gambar, audio, maupun video baik yang bersifat statis maupun dinamis yang saling terkait satu sama lain dan hihubungkan oleh jaringan jaringan halaman (hyperlink). Website disimpan di dalam server hosting yang dapat diakses lewat jaringan seperti jaringan Internet atau lewat jaringan 
area lokal lewat alamat Internet yang juga dikenal dengan nama uniform resource locator (URL). Website yang dapat diakses tersebut secara kolektif disebut world wide web (WWW) [6].

\section{E. Personal Home Page}

Bahasa pemrograman PHP juga disebut sebagai bahasa scripting atau bahasa pemrograman yang embedded yang artinya hanya perlu membaca sintaks dalam memproses pemrograman. Secara singkat sejarah bahasa pemrograman PHP [7].

PHP atau singkatan dari Personal Home Page merupakan bahasa skrip yang tertanam dalam HTML untuk dieksekusi bersifat server side".PHP termasuk dalam open source product, sehingga source code PHP dapat diubah dan didistribusikan secara bebas [8].

\section{F. Database MySQL}

MySQL merupakan salah satu DBMS yang familiar digunakan dengan total 6 juta instalasi di dunia. Kelebihan $M y S Q L$ diantaranya bisa digunakan pada semua sistem operasi seperti Linux, Mac OS X, Open BSD dan Windows secara gratis. MySQL juga bisa digunakan pada beberapa bahasa pemrograman, diantaranya yaitu bahasa pemrograman $\mathrm{C}, \mathrm{C}++$, Java, Perl, PHP, dan Ruby [9].

\section{Metodologi Penelitian}

Peneliti menggunakan metode ADDIE sebagai rancang bangun sistem dikarenakan model pengembangan ADDIE efektif, dinamis dan mendukung kinerja program itu sendiri [10]. Model ADDIE terdiri dari 5 komponen yang saling berkaitan dan terstruktur secara sistematis yang artinya dari tahapan yang pertama sampai tahapan yang kelima dalam pengaplikasiannya harus secara sistematik dan tidak bisa diurutkan secara acak. Kelima tahap atau langkah ini sangat sederhana jika dibandingkan dengan model desain yang lainnya. Adapun langkah penelitian pengembangan ADDIE dalam penelitian ini jika disajikan dalam bentuk bagan adalah sebagai

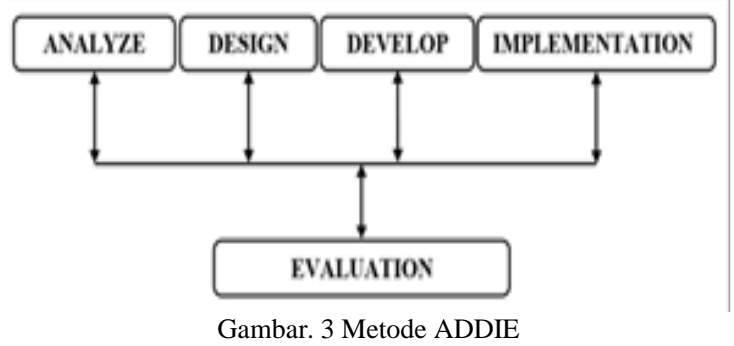

berikut.

\section{HASIN DAN PEMBAHASAN}

\section{A. Analisis}

Analisis pada tahapan ini mengidentifikasi serta mengevaluasi permasalahan yang ada di Fakultas Sains dan Teknologi, peluang dan halangan yang mungkin terjadi suatu saat ketika melakukan perancangan sehingga dapat dilakukan perbaikan pada tahap selanjutnya. Dalam hal ini permasalahan yang diangkat adalah kurang di perhatikannya aset intelektual mahasiswa dan belum adanya sistem yang mewadahi segala bentuk hasil keilmuan mahasiswa Fakultas Sains dan Teknologi. Sehingga segala bentuk aset intelektual yang dimiliki Fakultas Sains dan Teknologi perlu di tingkatkan

Dari permasalahan tersebut kemudian dianalisa apa saja yang dibutuhkan dalam pembuatan sistem. Dalam hal ini diperlukan dua jenis kebutuhan, yaitu kebutuhan fungsional dan non-fungsional. Adapun kebutuhan fungsional dan non-fungsional sebagai berikut ini :

1. Kebutuhan fungsional terkait alur proses sistem informasi yang berjalan adalah:

- Admin mahasiswa dapat menyimpan dan mengupload produk yang dimiliki.

- Admin mahasiswa dapat menyimpan dan mengupload prestasi yang dimiliki.

- Admin mahasiswa dapat menentukan forum diskusi.

- Mahasiswa dapat mengupload literatur di sistem.

- Upload literatur dapat berupa dokumen pdf.

- Mahasiswa dapat melakukan pencarian dengan menginputkan keyword.

- Admin mahasiswa dapat memantau progres hasil dari sistem.

- Data yang sudah diupload oleh mahasiswa tidak akan ditampilkan sebelum mendapat verifikasi dari admin pegawai yang mengurus kemahasiswaan tersebut.

- Admin pegawai dapat menverifikasi data yang di upload mahasiswa.

- Admin pegawai dapat memantau segala progres dari kegiatan keilmuan mahasiswa.

2. Kebutuhan non fungsional dalam menjalankan sistem informasi ini bisa dijalankan melalui laptop, PC, maupun smartphone karena sistem informasi berbasis website. Selanjutnya dalam pembuatan sistem dibutuhkan perangkat keras dan perangkat lunak sebagai berikut :

- Intel pentium 4 atau AMD athlon x64/x86 prosessor

- Microsoft dan windows 8.1

- RAM 2 GB

- 1024x768 display 16-bit color

- 512 MB of VRAM

Dalam pembuatannya dibutuhkan perangkat lunak sebagai berikut:

- XAMPP

- Visual studio code atau notepad++

- Web browser

- Framework codeigniter

- Adobe photoshop untuk mengedit gambar 


\section{B. Desain}

Untuk mendesain sistem informasi ini dibutuhkan context diagram dan DFD untuk menganalisa kebutuhan pengguna dan PDM untuk mendesain sistem.

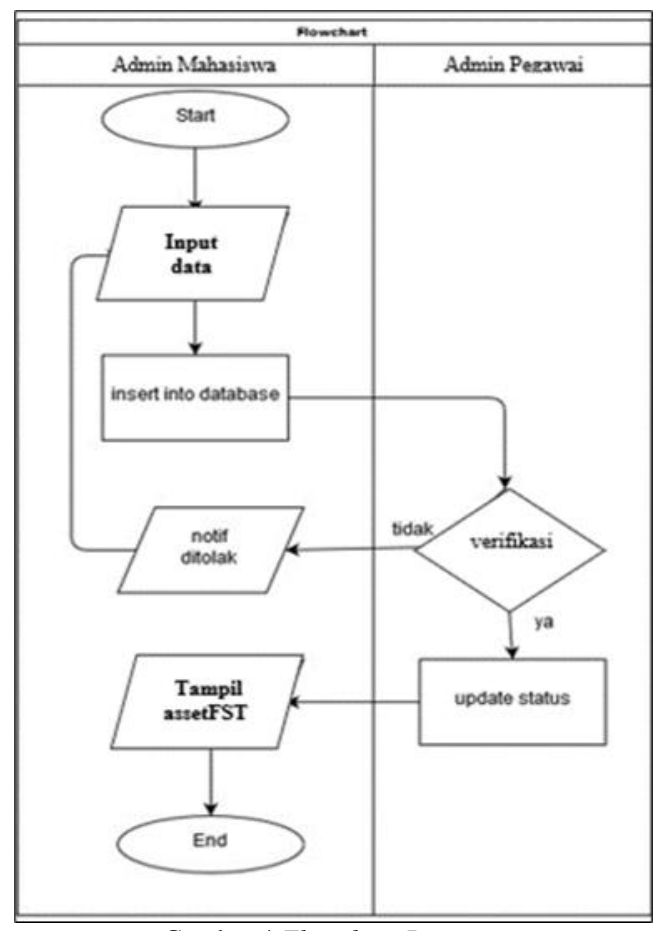

Gambar 4 Flowchart Program

\section{Flowchart}

Pada gambar di atas alur program secara garis besar dapat dijelaskan yaitu admin mahasiswa dapat menginputkan data kemudian data tersebut belum bisa ditampilkan dan harus menunggu verifikasi dari admin pegawai. Jika data belum terverifikasi, maka pada halaman admin mahasiswa akan muncul notifikasi bahwa datanya masih pending, sedangkan jika data diverifikasi maka otomatis data tersebut akan ditampilkan di halaman utama Aplikasi KMS. Penginputan data dilakukan oleh admin mahasiswa dari tiap prodinya masing-masing, mahasiswa lain juga bisa menginputkan data namun harus menunggu verifikasi dari admin pegawai.

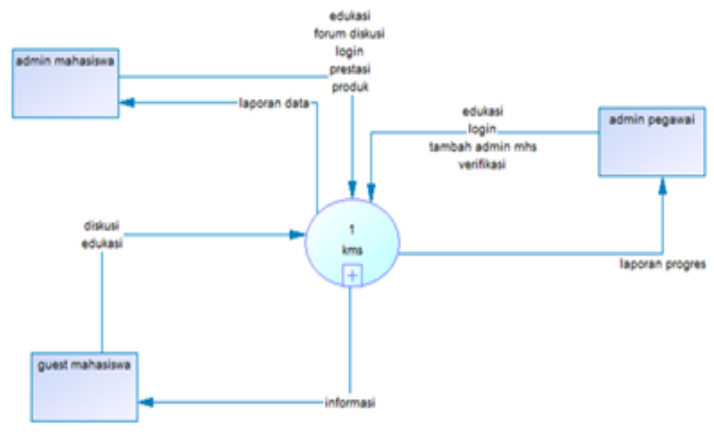

Gambar. 5 Context Diagrams

\section{Data Flow Diagrams}

Pada gambar di atas menjelaskan context diagram yaitu admin mahasiswa dapat login pada sistem dan mendapat feedback berupa laporan dari data yang telah di inputkan. Admin pegawai juga dapat login pada sistem dan mendapatkan feedback laporan progres mahasiswa dari setiap data yang di proses. Pengguna mahasiswa atau pengguna sistem mendapatkan informasi dari setiap data yang di input, serta dapat berdiskusi antar pengguna sistem. Selanjutnya gambaran dari alir data sistem secara

\section{Gambar. 5 Context Diagrams}

keseluruhan pada diagram level 1 sebagai berikut :

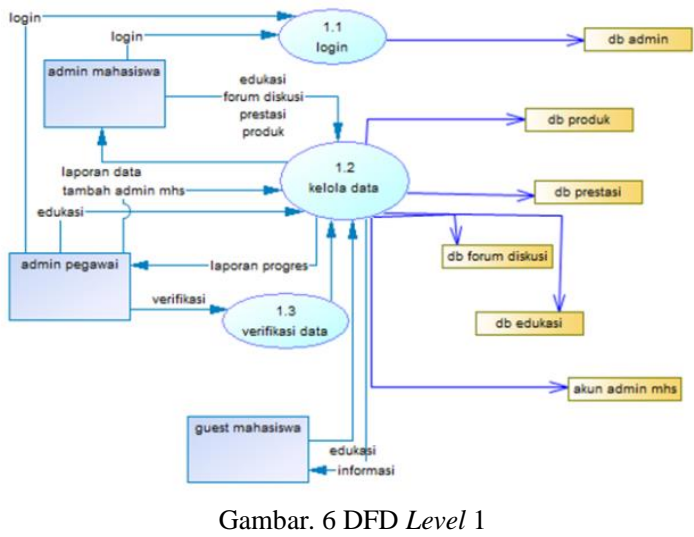

3. Conceptual Data Model

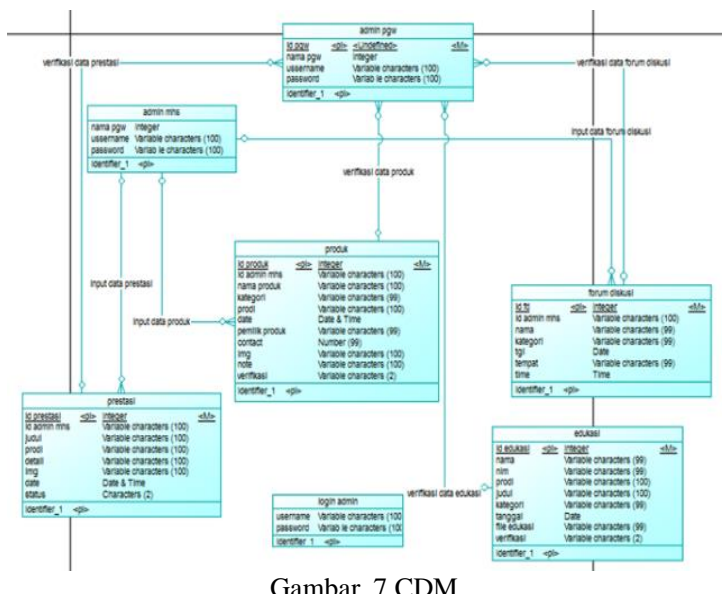

Pada gambar di atas menunjukkan serangkaian konsep yang saling berelasi sesuai dengan kebutuhan rancangan sistem. Berikut adalah penjelsan dari rancangan CDM tersebut:

- Tabel login digunakan untuk keamanan akun admin mahasiswa dan akun admin pegawai

- Tabel admin mahasiswa untuk menampung data admin mahasiswa dari enam prodi yang ada di fakultas sains dan teknologi.

- Table admin pegawai untuk menampung data admin pegawai yang memilik tugas seputar kemahasiswaan dari kegiatan sampai ke keilmuan mahasiswa di enam prodi fakultas 
sains dan teknologi.

- Tabel prestasi digunakan untuk menampung data yang sudah di input oleh admin mahasiswa dan sudah di verifikasi oleh admin pegawai.

- Tabel produk digunakan untuk menampung data yang sudah di input oleh admin mahasiswa dan sudah di verifikasi oleh admin pegawai.

- Tabel forum diskusi digunakan untuk menampung data diskusi mahasiswa

- Tabel edukasi digunakan untuk menampung data yang di input oleh user mahasiswa dan di verfikasi oleh admin pegawai.

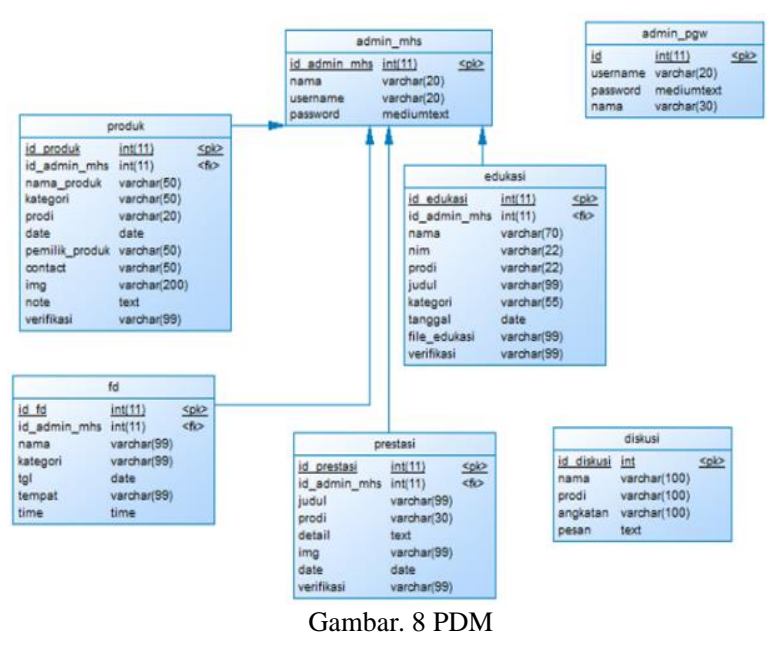

\section{Phisical Data Model}

Pada gambar diatas telah jelas tipe data dan telah muncul foreign key yang telah terbentuk pada relasi CDM sebelumnya. Pada PDM ini juga telah ditambahkan beberapa kolom yang dirasa perlu namun di CDM tidak dicantumkan. penjelasan PDM berelasi sebagai berikut :

- Tabel admin mahasiswa yang diberi nama "admin mhs" merupakan data mahasiswa yang memiliki primary key 'id mhs yang akan menjadi foreign key pada tabel "prestasi","produk" dan "forum diskusi”.

- Tabel admin pegawai yang diberi nama "admin pgw" merupakan data dosen yang memiliki primary key id admin pgw yang akan menjadi foreign key pada tabel "admin ussername".

- Tabel admin mahasiswa yang diberi nama "admin mhs" merupakan data mahasiswa yang memiliki primary key 'id mhs yang akan menjadi foreign key pada tabel "prestasi","produk" dan "forum diskusi",

- Tabel admin pegawai yang diberi nama "admin pgw" merupakan data dosen yang memiliki primary key id admin pgw yang akan menjadi foreign key pada tabel "admin ussername".

- Tabel prestasi,produk,forum diskusi merupakan tabel inputan dan penyimpanan data yang ada di dalam admin mahasiswa. Di tabel ini juga ada kolom tambahan yaitu id nya masing-masing dari setiap tabelnya. Kolom itulah yang membedakan kategori pada tiap data. Kemudian ada kolom "status" untuk mengetahui apakah data yang telah diupload telah diverifilkasi, atau belum. Jika belum maka kolom ini akan terisi "pending", dan jika diverifikasi akan terisi "post".

- Tabel edukasi merupakan tabel inputan dan penyimpanan data yang ada di dalam admin pgw. Di tabel ini juga ada kolom tambahan yaitu "id_edukasi" dari tabel edukasi. Kemudian ada kolom "verifikasi" untuk mengetahui apakah data yang telah diupload telah terverifikasi, atau belum. Jika belum maka kolom ini akan terisi "pending", jika disetujui akan terisi "post". Data edukasi tersebut akan di simpan di dalam admin pegawai.

- Tabel admin merupakan tabel untuk manajemen login administrator ke system tabel yang di gunakan untuk admin masuk ke halaman.

\section{Development}

Aplikasi ini menggunakan framework coedigniter dengan konsep MVC (Model, View, Controling). Aplikasi KMS ini memiliki multi login, yaitu admin mahasiswa, dan admin pegawai. Meskipun antara mahasiswa dan pegawai berbeda level login namun hampir secara keseluruhan memiliki desian usser interface yang sama. Sedangkan untuk admin pegawai berbeda karena memiliki hak akses verifikiasi data.

Alur model dalam sistem berhubungan dengan data dan interaksi ke database atau webservice. Didalamnya model berisikan class dan fungsi untuk mengambil, melakukan update dan menghapus data website. Apliaksi KMS ini menggunakan basis data dalam menyimpan data pada bagian model berisikan perintah - perintah yang berhubungan dengan querySQL. Berikut struktur model yang telah di bangun :

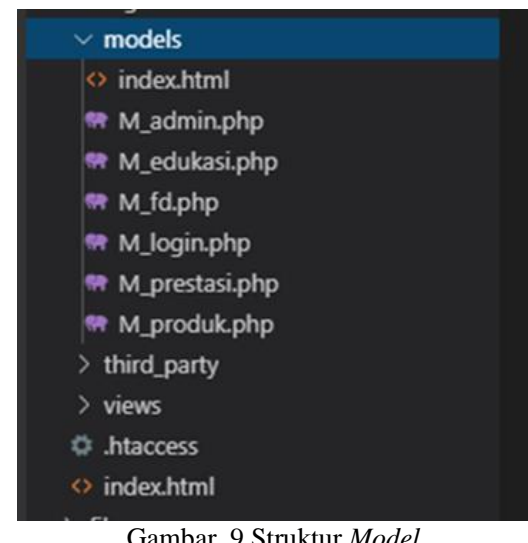

View dalam sistem yang di bangun, memuat segala macam tampilan aplikasi yang di butuhkan, struktur souce code di dalamnya secara khusus memuat tampilan keselurhan sebagai berikut : 


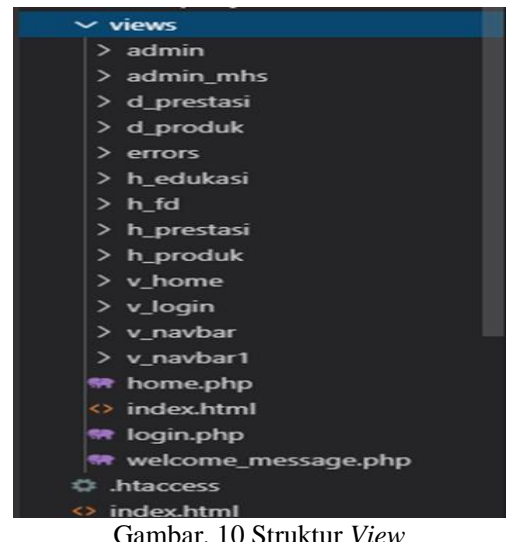

Gambar. 10 Struktur View

Controller dalam sistem yang dibangun, mengatur hubungan antara bagian model dan bagian view. Pada controller berisikan class-class dan fungsi-fungsi yang memproses permintaan dari view ke dalam struktur data di dalam model. Controller dalam sistem menyediakan berbagai variable yang akan ditampilkan di view, memanggil model untuk melakukan akses ke basis data, menyediakan penanganan kesalahn/error, mengerjakan proses logika dari aplikasi serta melakukan validasi atau cek terhadap input. Sebagai berikut :

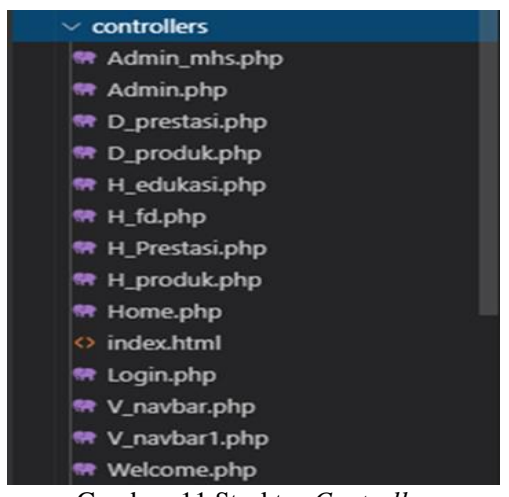

Gambar. 11 Struktur Controller

Selanjutnya untuk penyimanan data sistem menggunakan database MySQL. Dengan struktur data sebagai berikut :

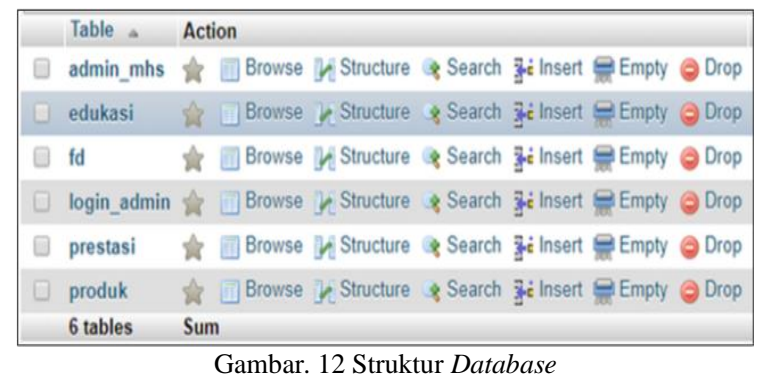

\section{Implementasi}

Tahap mengimplenetasikan semua desain atau perancangan sistem yang telah dibuat pada tahapan sebelumya kedalam sebuah aplikasi, dengan menggunakan tools dan konsep yang telah di pilih. Hasil dari perncangan saplikasi sebagai berikut :

a. Halaman login digunakan untuk memasukkan ussername dan password agar admin bisa masuk ke dalam sistem. Berikut ini adalah tampilan halaman login :

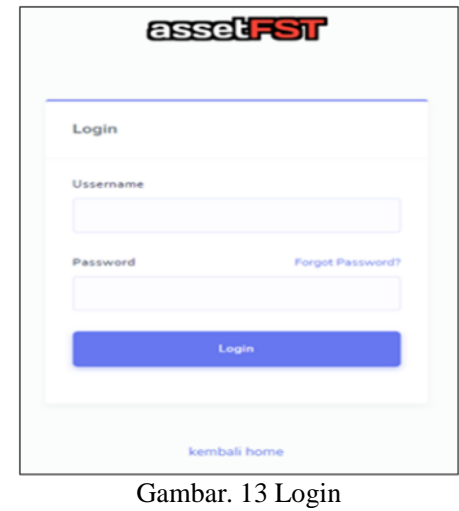

b. Halaman admin mahasiswa terlihat statistik data di setiap bulan dan di sebelahnya terdapat progres

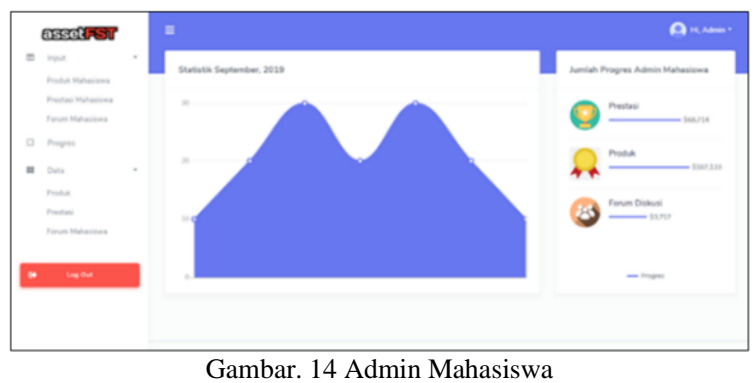

admin mahasiswa, di sebelah kiri terlihat menu bar untuk input, edit dan hapus data.

c. Halaman admin pegawai ada statistik data di setiap bulan dan di sebelahnya terdapat progres dari setiap admin mahasiswa, di sebelah kiri terlihant menu bar untuk menginputkan, meng edit dan menyimpan data serta mengverifikasi data yang di inputkan admin mahasiswa.

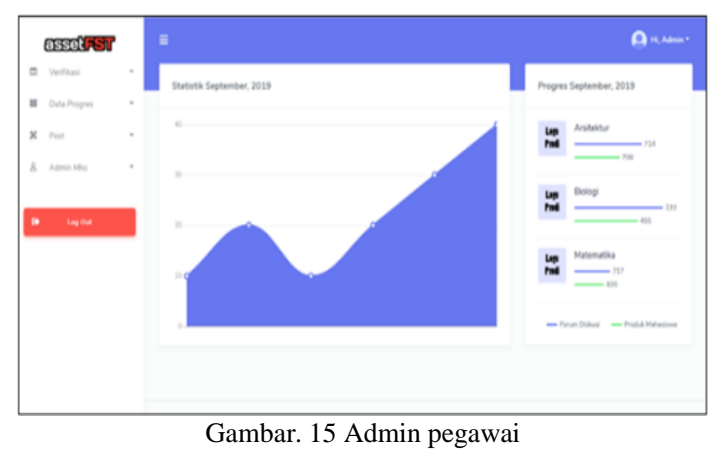

d. Halaman utama digunakan untuk media informasi dari setiap inputan yang telah terverifikasi. Halaman ini menjelaskan bahwa tampilan utama pada aplikasi knowledge management System, terlihat bahwa pada aplikasi tersebut terdapat menu dengan beberapa fugsi yang berbeda serta menu dengan manajemen pengetahuan lainnya. Untuk dapat menambah prestasi, produk serta mengupload dokumen edukasi yang diperlukan hak sebagai admin, selain itu terdapat fungsi mengupdate forum diskusi yang hanya bisa dilakukan dengan hak akses admin. 


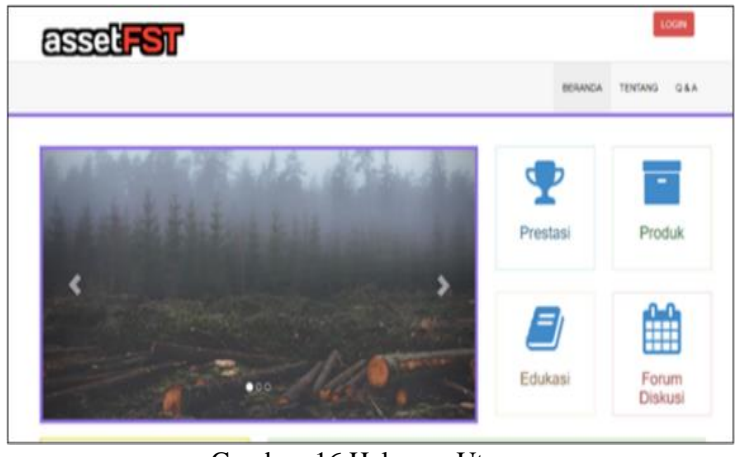

Gambar. 16 Halaman Utama

e. Halaman forum diskusi, dapat dimanfaatkan sebagai sarana knowledge sharing baik itu antar mahasiswa setiap prodi yang mengakses forum tersebut. Pada forum tersebut terdapat kategori yang hanya dapat dibuat oleh hak akses admin dan didalam kategori terdapat topik, waktu dan tempat

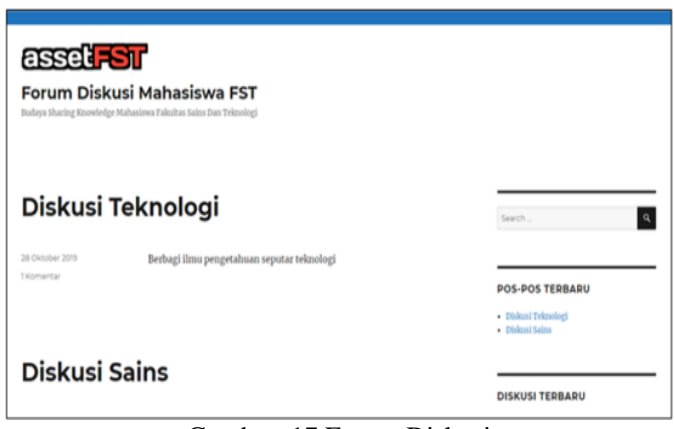

Gambar. 17 Forum Diskusi

yang telah di tentukan seperti gambar berikut :

f. Halaman edukasi merupakan contoh tacit menjadi explicit yang merupakan interaksi antara user mahasiswa yang membagikan refrensi belajar mahasiswa di fakultas sains dan teknologi. Transfer pengetahuan dari tacit menjadi explicit dapat berupa pengetahuan yang dikonversikan ke dalam dokumen baik dalam bentuk kertas ataupun arsip fisik lainnya. Didalam knowledge management system pengetahuan tacit dapat dipublikasikan ke dalam format digital atau berbasis website yang tersimpan dalam database sehingga tingkat kerusakan ataupun kehilangan dapat diminimalisir:

g. Halaman produk merupakan dokumentasi dari suatu tacit menjadi explicit, pengetahuan explicit menjadi digital dan tersimpan dalam database. Sebagai contoh mempublikasikan suatu info

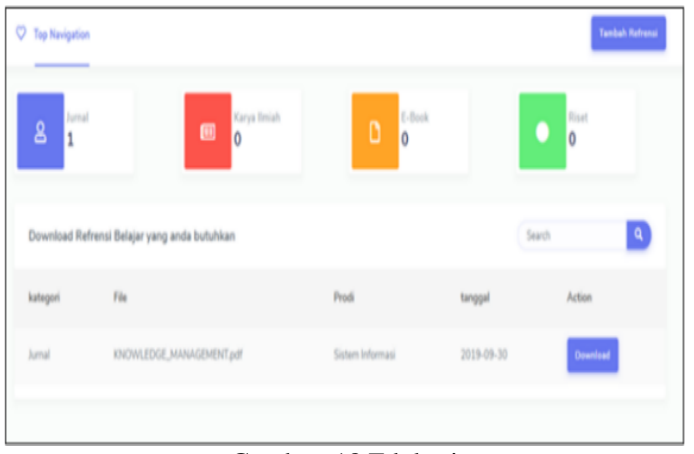

tentang produktifitas mahasiswa kepada publik, karna para mahasiswa di fakultas sains dan teknologi seringkali mengikuti pelatihan, praktek serta seminar yang biasa dilakukan mahasiswa, agar knowledge tidak berhenti pada satu mahasiswa atau satu prodinya saja, oleh karena itu knowledge dapat dibagikan kepada para mahasiswa lain maupun kepada mahasiswa yang membutuhkan dan dipublikasikan dalam apikasi. Proses transfer pengetahuan dari explicit menjadi explicit yaitu didalam fakultas sains dan teknologi selalu ada pendokumentasian dalam bentuk berkas-berkas fisik, baik itu data-data tentang prestasi mahasiswa lainnya yang membuat mahasiswa semangkin termotivasi.

h. Halaman prestasi merupakan pengarsipan dokument prestasi yang selalu diperbaharui dari waktu ke waktu seperti. Transfer pengetahuan dari

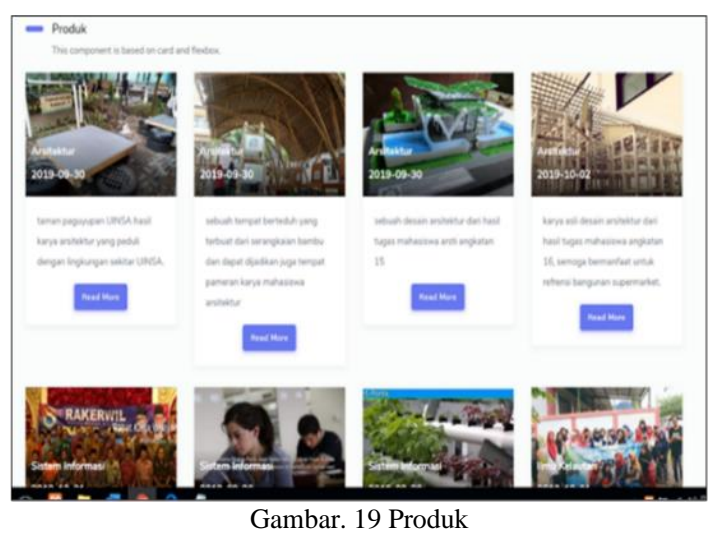

explicit menjadi tacit seperti publikasi hasil prestasi mahasiswa yang membuat publik mampu mengetahui prestasi mahasiswa fakultas sains dan teknolgi.

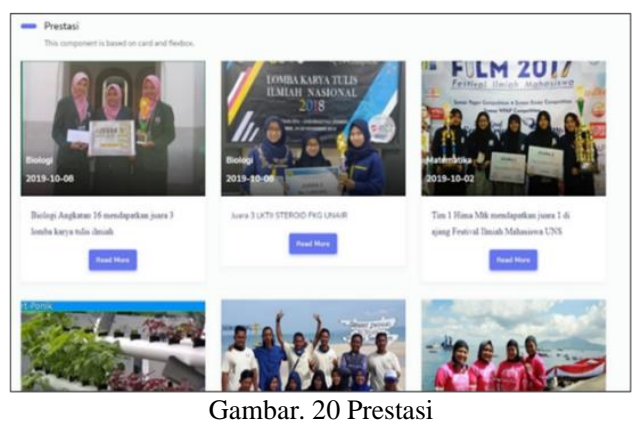

\section{E. Evaluasi}

Tahapan ini peneliti menggunakan evaluasi kuantitatif yang di peroleh dari analisis data responden dalam bentuk angka pada angket yang di berikan. Jumlah responden di ambil 60 dari berbagai bidang keilmuan di Fakultas Sains dan Teknolgi, pembagian kuesioner tersebut dibuat dalam bentuk skor lima point dengan model skala likert untuk mengukur persetujuan 
pengguna Data diperoleh dari hasil pengisian kuisioner tersebut oleh 60 responden mahasiswa untuk menilai kelayakan sistem sebagai berikut:

1. Hasil kuesioner prodi arsitektur dengan total 820 dan persentase nilai sebesar $82 \%$.

2. Hasil kuesioner prodi biologi dengan total 872 dan persentase nilai sebesar $87,2 \%$.

3. Hasil kuesioner prodi matematika dengan total 869 dan persentase nilai sebesar $86,9 \%$.

4. Hasil kuesioner prodi sistem informasi dengan total 839 dan persentase nilai sebesar $83,9 \%$,

5. Hasil kuesioner prodi ilmu kelautan dengan total 873 dan persentase nilai sebesar $87,3 \%$.

6. Hasil kuesioner prodi teknik lingkungan Kelautan dengan total 893 dan persentase nilai sebesar $89,3 \%$.

Selanjutnya dari data-data tersebut kemudian dihitung persentase totalnya dengan rumus :

$P=($ Total Skor $/ Y) \times 100$

(1)

Menjadi :

$\boldsymbol{P}=\left(\frac{820+872+869+839+873+893}{5 \times 60 \times 20}\right) \times 100=\mathbf{8 6 , 1} \%$

(2)

sehingga menurut nilai interval $86,1 \%$ sudah memenuhi kelayakan aplikasi sebagaimana tabel interval berikut :

Table 1 Interval Kategori Kelayakan

$$
\text { Angka Kategori }
$$

\begin{tabular}{ll}
\hline $0 \%-19,99 \%$ & Sangat tidak setuju / Buruk / \\
& Kurang Sekali \\
$20 \%-39,99 \%$ & Tidak Setuju \\
$40 \%-59,99 \%$ & Netral / Cukup \\
$60 \%-79,99 \%$ & Setuju / Baik \\
$80 \%-100 \%$ & Sangat setuju / Sangat Baik
\end{tabular}

\section{KESIMPULAN DAN SARAN}

Penelitian ini berhasil merancang bangun aplikasi aset intelektual Berbasis knowledge management system untuk membantu mahasiswa meningkatkan aset intelektual di Fakultas Sains dan Teknologi. Dimana proses tacit knowledge menjadi explicit knowledge dapat menciptakan pengetahuan baru melalui budaya sharing knowledge antar mahasiswa dari setiap program studi di Fakultas Sains dan Teknologi sehingga dapat meningkatkan produktifitas dan prestasi mahasiswa. Selain itu saran penelitian selanjutnya di harapkan dapat dikembangkan lagi dalam sistem operasi android, penelitian selanjutnya meningkatkan penggunaan warna yang menarik pada desain interface dan Penambahan inovasi fitur yang lebih bisa menampung aspirasi pengguna mahasiswa terkait fasilitas yang dibutuhkan untuk pengembangan KMS.

\section{REFERENCES}

P. L. Tobing, Knowledge management: Konsep, arsitektur dan implementasi, 1st ed. Yogyakarta: Graha Ilmu, 2007.
Penerbit Lokomedia, 2011

[3] K. dan I. N. Ichijo, "Knowledge Creation and Management," in New Challenges for Managers., New York Oxford University Press, 2007.

[4] Shelda Debowski, Knowledge Management. Wiley Press, 2006.

[5] Lukmanul Hakim, Membangun Web Berbasis PHP dengan Framework Codeigniter. Lokomedia, 2010.

[6] D. Anggriani, "Perancangan Website Sebagai Media Promosi Sentra Industri Kecil Konveksi Batik Mlangi," Fakultas Teknologi Industri, Universitas Atma Jaya, Yogyakarta., 2012.

[7] tendy B. Sakur, PHP 5 Pemrograman Berorientasi Objek-Konsep \& Implementasi. yogyakarta: CV. Andi Offset (Penerbit Andi)., 2010.

[8] Bunafit Nugroho, "Membuat Aplikasi Sistem Pakar dengan PHP dan My SQL," Dreamweaver, Ed. Yogyakarta: Ardana Media, 2006.

[9] W. J. Gilmore, Beginning PHP and MySQL From Novice to Professional Fourth Edition. United States America, 2010.

[10] R. Wijayanto and H. R. SAntoso, "Pengembangan Bahan Ajar Matematika Dengan Pendekatan Problem Solving Berorientasi Pada Kemampuan Pemecahan Masalah," no. $1,2010$. 